\title{
INFLUENCE OF RUNNER ANGLES ON BALANCED FILLING FOR MULTICAVITY MOULDING
}

\author{
Karel Raz, Zdenek Chval, Roman Polak
}
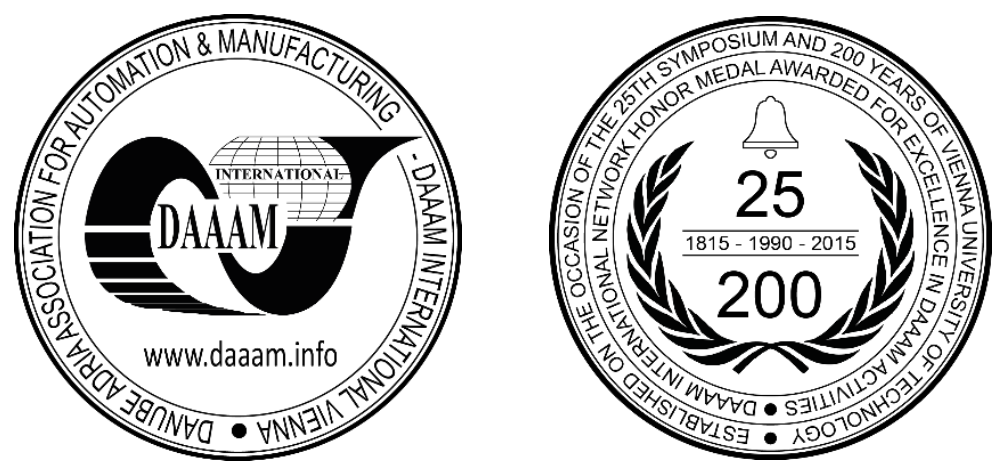

This Publication has to be referred as: Raz, K[arel]; Chval, Z[denek] \& Polak, R[oman] (2018). Influence of Runner Angles on Balanced Filling for Multicavity Moulding, Proceedings of the 29th DAAAM International Symposium, pp.0653-0658, B. Katalinic (Ed.), Published by DAAAM International, ISBN 978-3-902734-20-4, ISSN 1726-9679, Vienna, Austria

DOI: $10.2507 / 29$ th.daaam.proceedings.094

\begin{abstract}
This paper deals with the influence of runner angles on the balanced filling of a three-cavity mould during injection moulding. The main goal of the study is to understand the influence of the angles between the runners and the balanced filling of the three individual parts. Balanced filling leads to better visual and mechanical properties of the final product. Different mould flow simulations with the same processing parameters (material, temperature, pressure and time) were performed to observe the influence of the runner angle. Polypropylene was used as the reference material in this paper. A simple cylindrical part was considered here. In essence, it seems to be a very simple situation, however before running the mould flow simulations there was no general notion of the results and their justification. The paper also raises the possibility for modifying filling behaviour by changing the runner angles and evidence that the configuration with 90 degrees between each runner is the most suitable for achieving the filling of the three parts at the same time.
\end{abstract}

Keywords: injection moulding; multicavity moulding; runner angles; balanced filling; mould-flow

\section{Introduction}

There are a lot of papers in the literature regarding the importance of having balanced filling of all multicavity parts during injection moulding, mainly after the invention of many types of CAD software to develop and to optimize performance for an educational platform considering various manufacturing scenarios [1], [2].

Early runner balancing studies assumed that balanced filling considers only obtaining all parts filling at the same time [3]. However, some authors [4] argued that this criterion is insufficient, since it does not consider packing effects. In this scenario, a more current definition is that balanced filling in a multicavity mould involves designing the runners in order to fill all the parts at the same time at the same temperature, aiming to pack all the parts with the same density and shrinkage [5]. An Intelligent Cavity Layout Design System was developed for multiple cavity injection moulds, which is believed to be the first attempt in this direction using a knowledge-based approach. It shows us that we can have an imbalanced filling even when using a balanced runner system [6], [7].

All these works refer to the importance of having an equal filling of all cavities, however nothing was found relating the influence of different runner angles to a balanced filling for a three-cavity moulding. 
Based on this some very basic models were created using NX 11.0 with different runner angles. All these designs were sent to Moldex3D R15.0 to run the injection simulations, aiming to better understand the flow behaviour for different runner angles and their influence on balanced injection filling.

\section{Method}

As mentioned in the Introduction, the simplest possible model was designed in order to evaluate just the influence of the runner angle. The entire kit with runners and parts was drawn using NX 11.0. The runners were considered to be cylindrical, because the full-rounded shape is the most efficient runner system, since it minimizes liquid resistance and temperature reduction as mentioned [8], [9].

The parts were considered to be cylinders. It is important to clarify that although injection moulding is not a suitable process for manufacturing cylindrical shapes, this shape was used because of its simplicity. See Fig 1 for the model with all its dimensions.

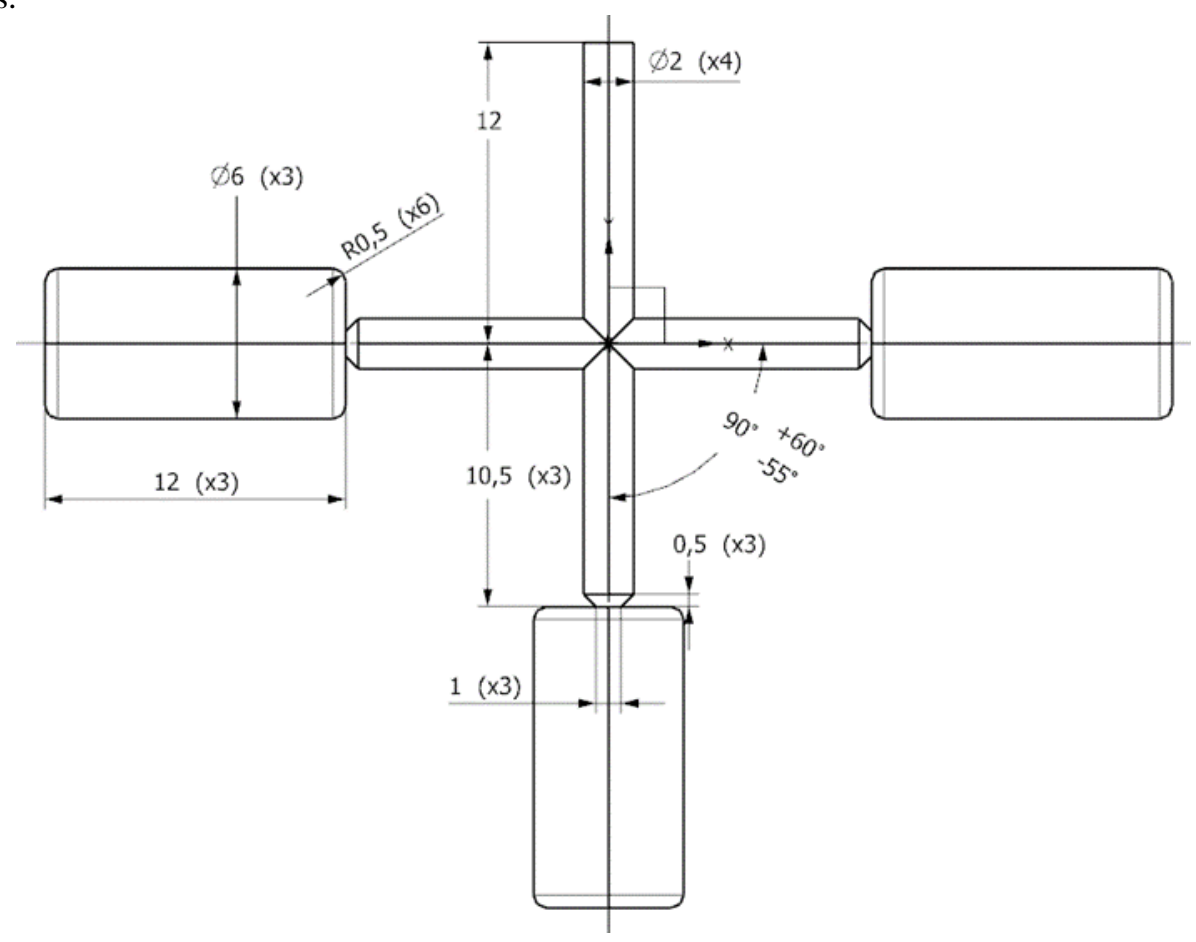

Fig. 1. Drawing of part plus runners used in the study case.

Small dimensions were chosen because we intend to have a small set that can enable faster software analysis [10], [11]. We considered different runners using angles from 35 - 150 degrees: 35 degrees, 45 degrees, 60 degrees, 75 degrees, 90 degrees, 100 degrees, 120 degrees, 135 degrees and 150 degrees.

All these models were imported to Mouldex3D R15.0 Designer to create a mesh file for injection moulding. The entire set was considered as the part and the melt entrance was specified as the transversal face of the runner without a part connection. A cooling channel was not considered and it was not created for the moulding. All mesh models were generated using a mesh size of 0.2 and the parting direction setting was in the $\mathrm{Z}$ axis.

After mesh creation all models were imported to Mouldex3D R15.0 for the injection simulation. The material used in the simulations was PP CP 442 XP from the manufacturer Braskem. As we just want to monitor the influence of the angle of the runners, all injections were carried out considering the default process parameters of this material in the software. The standard computation parameters were used, except that we increased the filling and packing analysis to 10 equally spaced steps, aiming to better observe the different phases of the simulation. Gravitational force was disregarded for the simulations, since it does not show a significant influence on the filling [12], [13].

In order to analyse the balanced filling of parts, the following method was used: The filling time was observed considering four decimal points and visually the time that the first cavity was filled was chosen. To find the percentage of parts unfilled at this moment, we chose as a base the volume fraction of filling. The time of the first filled part in the volume fraction graph was set in order to discover the volume \% of the missing parts [14], [15].

Aiming to set a more accurate point, the $\mathrm{X}$ and $\mathrm{Y}$ axes were plotted with 20 tick marks and 4 number digits. Considering the method above, when the first part is filled we have $96.6705 \%$ of volume fraction filled. However, this is the volume fraction considering the runners and parts. To obtain just the volume fraction of the parts that are not filled, we used equation (1): 
$\% \mathrm{VP}=\frac{\left(\frac{100-\% V F}{n}\right) \times 0,01 \times V T}{V P}$

Where:

- $\%$ VP: \% other part volume missing at the moment the first part is filled;

- $\%$ VF: Percentage of volume filled;

- n: number of parts that are not filled at the first cavity filling. It can be 1 or 2 depending if (1) the middle part or (2) the side parts fill first;

- VT: Total volume of the runners and parts measured by NX 11.0;

- VP: Part volume measured by NX 11.0.

\section{Results}

After running all the analyses, we obtained the results given in Table 1.

\begin{tabular}{|c|c|c|}
\hline $\begin{array}{c}\text { Angle } \\
\text { (degrees) }\end{array}$ & First Part Filled & \% VP \\
\hline 35 & middle & $4.64 \%$ \\
\hline 45 & middle & $5.62 \%$ \\
\hline 60 & middle & $3.15 \%$ \\
\hline 75 & middle & $0.96 \%$ \\
\hline 90 & All the same time & $0.00 \%$ \\
\hline 100 & right and left & $-1.63 \%$ \\
\hline 120 & right and left & $-4.78 \%$ \\
\hline 135 & right and left & $-9.11 \%$ \\
\hline 150 & right and left & $-19.49 \%$ \\
\hline
\end{tabular}

Table 1. Results of simulations with different runner angles

The minus sign was introduced to differentiate models that did not fill the middle part first. To make it easier to compare the results, Graph 1 was created, where we can clearly check the visual difference between the results.

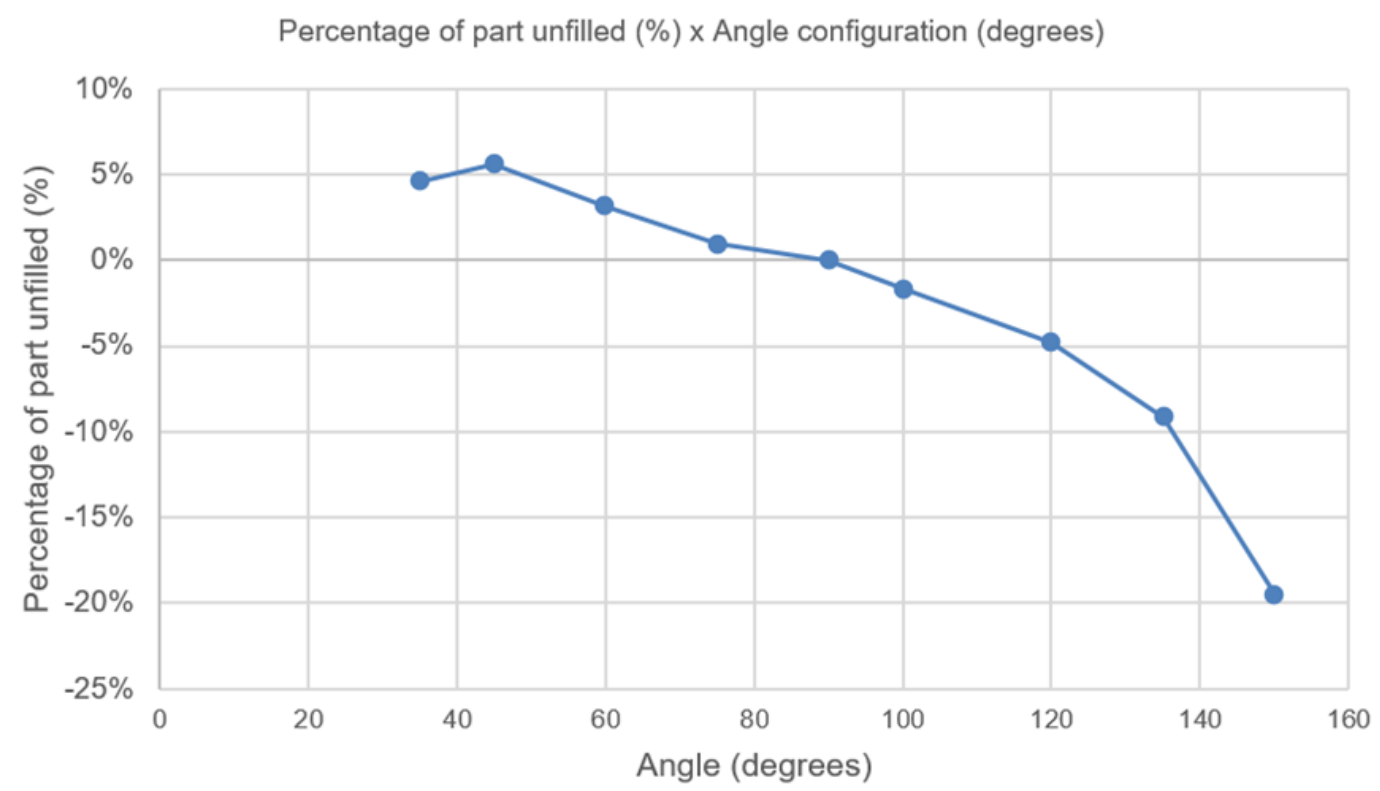

Graph 1. Percentage of part unfilled (\%) x Angle of configuration (degrees).

We can see that only the design configuration of 90 degrees filled all the parts at the same time. Lower angles than 90 degrees tend to fill the middle part first, and angles higher than 90 degrees tend to fill the side parts first. The results can be explained though the analysis of the flow behaviour during filling. Even when all runners are the same length, actually when we change the angles we change the volume and superficial area of each runner due to the overlap between them. Fig. 2 shows the velocity vector during the start of filling for the angles of 35 and 150 degrees. 


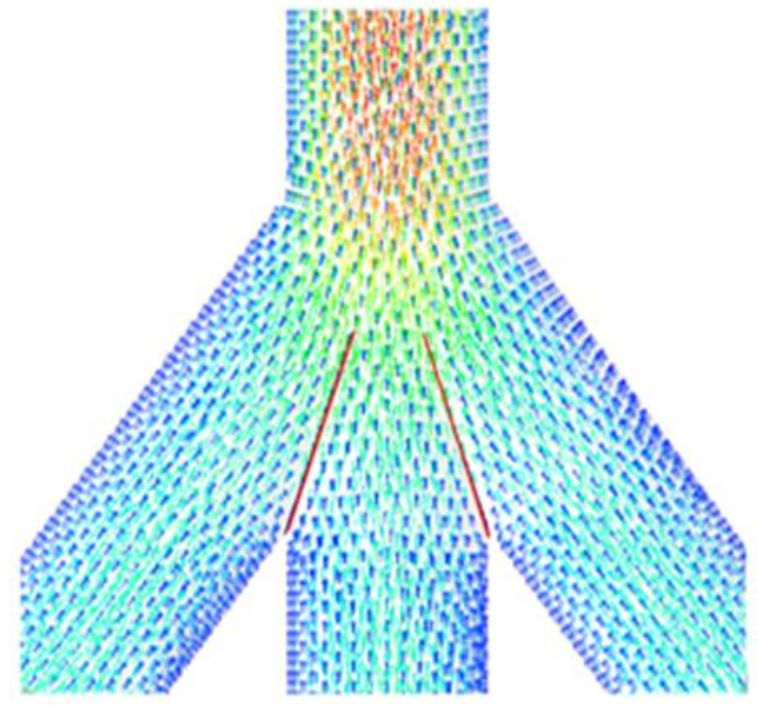

(a)

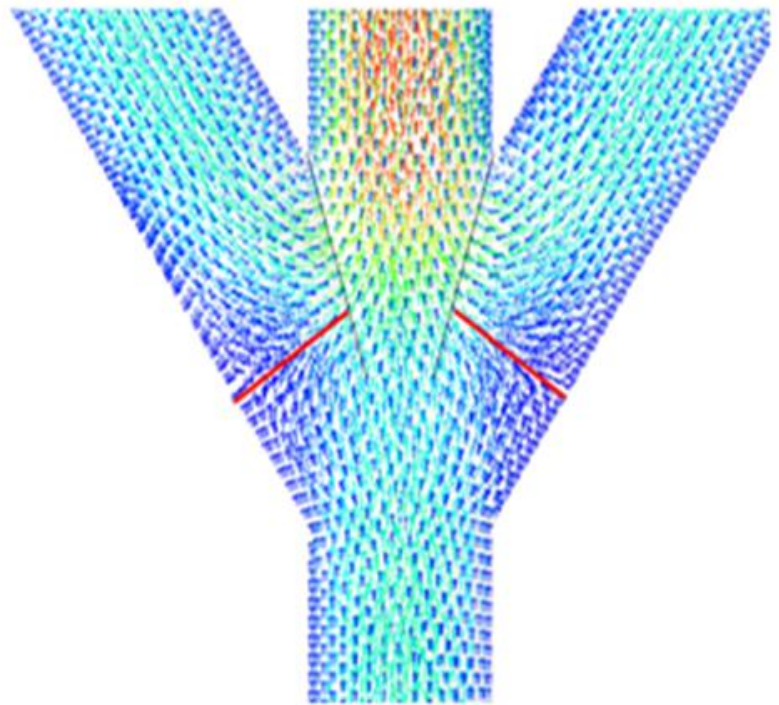

(b)

Fig. 2. Velocity vector of flow during the start of filling for models with runner angles of (a) 35 and (b) 150 degrees.

For the configuration of 150 degrees, despite the runners having the same length, the volume of flow is actually longer for the middle channel. The flow tends to go to each side in the same way. As it has a small volume for the side runners, this explains why the side runners are filled first for angles bigger than 90 degrees.

With angles lower than 90 degrees, the opposite happens. Despite the side runner decreasing its superficial area and its volume, actually the middle runner decreases its superficial area and its volume twofold due to an overlap with the side runners. Since the middle runner has a smaller volume and superficial area than the side runners, which explains why the middle runner is filled first for this configuration. In order to test this explanation, each runner for all configurations was measured using NX 11.0 and the results were in agreement with the above explanation.

In order to complement the work, we analysed the influence of having an edge between the runners and balanced filling. Therefore, all angle models simulated in the study were modified by adding an edge blend (marked by the red arrow in Fig. 3) with a radius of $1 \mathrm{~mm}$ between the runners.

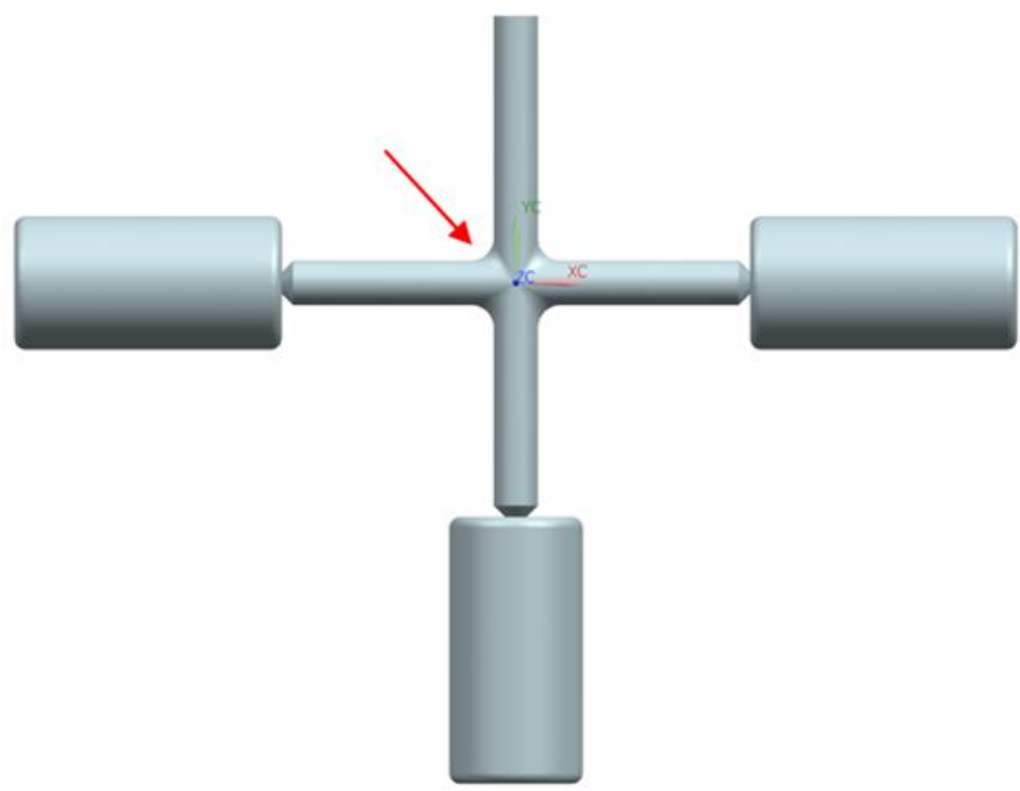

Fig. 3. 90 degree model with an edge radius $1 \mathrm{~mm}$ between the runners.

All these models were simulated using the same mould-flow software with the same parameters as used previously. Graph 2 presents the results of the simulations, comparing them with the same models without the edge between the runners. 


\section{Percentage of part unfilled (\%) x Angle configuration (degrees)}

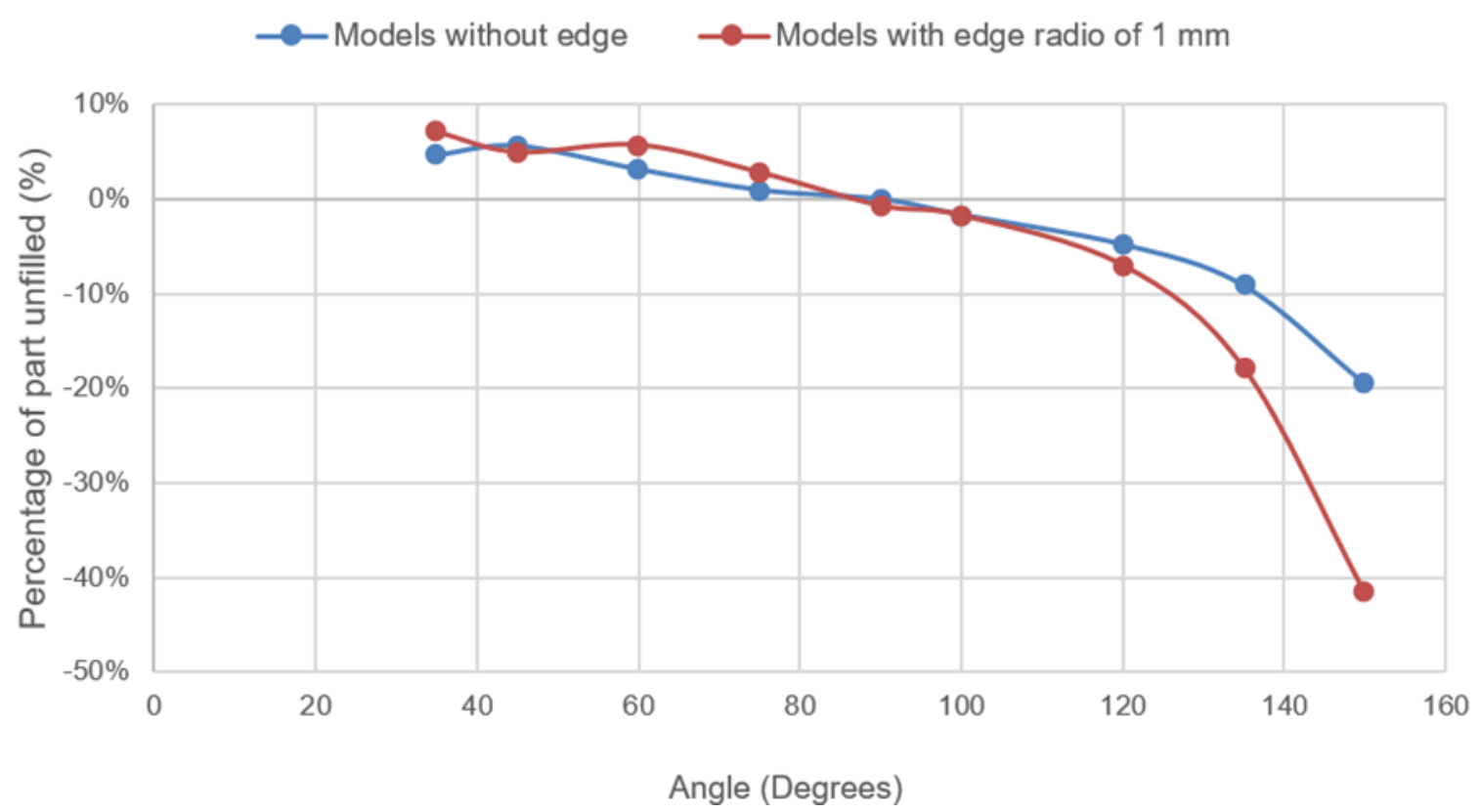

Graph 2. Comparison between models with and without edge between the runners. Percentage of part unfilled $(\%) \mathrm{x}$ Angle configuration (degrees).

Based on the results, we can see that the behaviour of the models with edges has the same pattern as without edges, however we can see that the curve with the edge blend is more sensitive, in other words, it has a more unbalanced filling of cavities. This trend to increasing the unbalanced filling with edge blending can be explained in the same way as in the previous analysis. Even though all the runners have the same length, actually when we change the angles using the edge between them, we change the volume and superficial area of each runner to a greater extent than without the edge due to a bigger overlap between them.

\section{Conclusion}

Computer-aided engineering (CAE) is very helpful for predicting flow behaviour. Based on the simulations, we noticed that the most suitable configuration was obtained with an angle of 90 degrees between the runners, since we have the same superficial area and volume for all 3 runners, resulting in an equal flow, which gives us the same filling time for all the parts. We also noted that by using edges between the runners we increased the unbalanced filling for these models.

This work suggests that despite having the same runner lengths, actually the flow area and volume of runners are not the same. We must be aware of the real volume flow of each channel and not just the length of them when we are designing them for injection moulding. The results have given us a good direction regarding the best runner design for a three-cavity mould. However, we need to be careful regarding the influence of gravity during practical tests.

For future work we recommend analysing the influence of changing the length of the runner channels, diameters and using other materials, in order to try to create a formula than can give us the requirements for filling all parts at the same time independent of the angle used. It would be also be interesting to perform practical tests to validate the simulations.

\section{Acknowledgments}

This paper has been prepared under project LO1502 'Development of the Regional Technological Institute' under the auspices of the National Sustainability Programme I of the Ministry of Education of the Czech Republic aimed at supporting research, experimental development and innovation.

\section{References}

[1] Polak, R., Sedlacek, F. \& Raz, K. (2017). Determination of FDM printer settings with regard to geometrical accuracy. In Proceedings of the 28th DAAAM International Symposium. Vienna: DAAAM International, 2017. pp. 561-566. ISBN: 978-3-902734-11-2, ISSN: 1726-9679, DOI: 10.2507/28th.daaam.proceedings.079

[2] Jenicek, S., Vratislav, K., Kalina, T. \& Masek, B. (2016). Use of waterjet in manufacturing test bars of high-strength steels, Annals of DAAAM for 2016 Proceedings of the 27th DAAAM International Symposium, pp.219- 224, B. 
Katalinic (Ed.), Published by DAAAM International, ISSN 1726-9679, Vienna, Austria, DOI: 10.2507/27th.daaam.proceedings.032

[3] Chval, Z., Cechura, M. (2014). Monitoring extremely stressed points on stands of forging presses, Annals of DAAAM for 2014 Proceedings of the 25th DAAAM International Symposium, pp.841- 846, B. Katalinic (Ed.), Published by DAAAM International, ISSN 18777058, Vienna, Austria DOI: 10.1016/j.proeng.2015.01.439

[4] Kim, J., Ahn, S., Atre, S., Park, S. J., Kang, T. G. \& German, R. M., Imbalance filling of multi-cavity tooling during powder injection moulding, Powder Technology 257 pp. 124-131, 2014

[5] Raz, K., Zahalka, M. \& Polak, R. (2016). Injection Molding Simulations Of Hardly Producible Parts From PBT, Annals of DAAAM for 2016 Proceedings of the 27th DAAAM International Symposium, pp.0501- 0505, B. Katalinic (Ed.), Published by DAAAM International, ISBN 978-3-902734-08-2, ISSN 1726-9679, Vienna, Austria DOI: $10.2507 / 27$ th.d

[6] Hu, W., Masood, S. (2002) An intelligent cavity layout design system for injection moulds, International journal of CAD/CAM Vol. 2, No. 1, pp. 69-75,

[7] Kalina, T., Sedlacek, F. \& Krystek, J. Determination of the influence of adherent surface on the adhesive bond strength, 22nd Slovak-Polish Scientific Conference on Machine Modelling and Simulations, MATEC Web of Conferences, Volume 157, Article Number 05012, ISSN 2261236X, DOI: 10.1051/matecconf/201815705012

[8] Yeager, M., Balanced Filling in Thermoplastic Medical Moulding, Medical Design Briefs, page 13-15, Volume 3 Number 10, October 2013. Available from: http://www.medicaldesignbriefs.com/component/content/article/17489 Accessed: 2018-04-06

[9] Steiner, F; Bleicher, F \& Klingenbrunner, M (2016). Emissivity Factor of Thermoplastic Materials for a Robot Bending Process, Proceedings of the 27th DAAAM International Symposium, pp.0664-0670, B. Katalinic (Ed.), Published by DAAAM International, ISBN 978-3-902734-08-2, ISSN 1726-9679, Vienna, Austria, DOI: 10.2507/27th.daaam.proceedings.096

[10] Spirk, S., Kepka, M. Tests and Simulations for Assessment of Electric Buses Passive Safety, Annals of 1st International Conference on Structural Integrity, pp.338- 345, Published by Elsevier Ltd, ISSN 18777058, DOI: 10.1016/j.proeng.2015.08.077

[11] Sedlacek, F., Bernardin, P. \& Lasova, V. (2017). Optimal design of a composite bellows coupling using a structural optimization. In AIP Conference Proceedings. Melville: American Institute of Physics Inc., 2017. pp. 050001-1 050001-6. ISBN: 978-0-7354-1518-8 , ISSN: 0094-243X, DOI: 10.1063/1.4983606

[12] Alam, K.; Kamal, M. R. (2005). A robust optimization of injection molding runner balancing. Computers and Chemical Engineering 29, Pages 934-1944, Canada,

[13] Huynh, H. N.; Verlinden, O. \& Riviere-Lorphevre, E. (2017). Robotic Machining Simulation using a Simplified Multibody Model, Proceedings of the 28th DAAAM International Symposium, pp.0885-0894, B. Katalinic (Ed.), Published by DAAAM International, ISBN 978-3-902734-11-2, ISSN 1726-9679, Vienna, Austria, DOI: 10.2507/28th.daaam.proceedings. 123

[14] Cotet, C. E.; Popa, C. L.; Enciu, G.; Popescu, A. \& Dobrescu T. (2016). Using CAD and Flow Simulation for Educational Platform Design and Optimization. International Journal of Simulation Modelling, Vol. 15, No. 1, 515, ISSN 1726-4529

[15] Markovicova, L., Zatkalikova, V. (2017). Corrosive effect of environmental change on selected properties of polymer composites, Annals of IOP Conference Series: Materials Science and Engineering, Published by Institute of Physics Publishing, ISSN 17578981, DOI: 10.1088/1757-899X/266/1/012010 